\title{
O ensino de espanhol em Jaguarão-Brasil: Estabelecendo experiências formativas e colaborativas com os professores municipais
}

\author{
La enseñanza de español en Jaguarão-Brasil: Estableciendo experiencias \\ formativas y colaborativas con los profesores municipales
}

\author{
The teaching of Spanish in Jaguarão-Brazil: Establishing formative and \\ collaborative experiences with municipal teachers
}

\section{Caroline Gonçalves Feijó-Quadrado}

Paula Bianchi ${ }^{2}$

\begin{abstract}
Resumo
A partir das últimas alterações realizadas na Lei de Diretrizes e Bases da Educação Nacional, a visão políticoeducacional brasileira coloca em nível de opcionalidade o ensino de língua espanhola nas escolas. Diante disso, os poderes Legislativos e Executivos estaduais e municipais, reconhecendo a importância do ensino deste idioma no currículo escolar, estão propondo ações locais para fazer com que a disciplina de espanhol permaneça sendo ofertada como obrigatória. Este é o caso do município de Jaguarão-Brasil, fronteiriço com Rio Branco-Uruguai, que incluiu o §6, no art. 134, da Lei Orgânica Municipal. Neste contexto, com a intenção de fortalecer o ensino de espanhol no Município, busca-se, por meio de pesquisa de mestrado em andamento, estabelecer com os professores de espanhol da rede municipal de Jaguarão experiências formativas e colaborativas (NÓVOA, 1992; SCHÖN, 2000; IMBERNÓN, 2010; TARDIF, LESSARD, 2008) voltadas para o ensino desta língua. Pretendese, neste trabalho, discutir os resultados colhidos durante a realização do diagnóstico da realidade. Metodologicamente, o estudo caracteriza-se como pesquisa-ação (THIOLLENT, 2009) e utiliza os seguintes instrumentos para obtenção dos dados: a) pesquisa documental; b) grupo focal; e c) questionário. Espera-se que a análise de conteúdo dos dados do diagnóstico contribua para o planejamento das ações formativas propriamente ditas, que terão os professores de espanhol do município como público-alvo.
\end{abstract}

Palavras-Chave: Formação continuada de professores; ações colaborativas; pesquisa-ação; ensino de espanhol.

\section{Resumen}

A partir de las últimas alteraciones realizadas en la Ley de Directrices y Bases de la Educación Nacional, la visión político-educativa brasileña coloca como opcional la enseñanza de lengua española en las escuelas. En consecuencia, los poderes legislativos y ejecutivos de los estados y municipios, reconociendo la importancia de la enseñanza de este idioma en el currículo escolar, están proponiendo acciones locales para hacer con que la disciplina de español permanezca siendo ofrecida como obligatoria. Este es el caso del municipio de JaguarãoBrasil, fronterizo con Rio Branco-Uruguay, que incluyó el §6, en el art. 134, de la Ley Orgánica Municipal. Con la intención de fortalecer la enseñanza de español en el Municipio, a través de investigación de maestría en marcha, se ha buscado establecer con los profesores de español de la red municipal de Jaguarão experiencias formativas y colaborativas (NÓVOA, 1992, SCHÖN, (2000), IMBERNÓN, 2010, TARDIF, LESSARD, 2008). En este trabajo, se pretende discutir los resultados obtenidos durante la realización del diagnóstico de la realidad. Metodológicamente, esta investigación se caracteriza como investigación-acción (THIOLLENT, 2009) y utiliza los siguientes instrumentos para la obtención de los datos: a) investigación documental; b) grupo focal; y c) cuestionario. Se espera que el análisis de contenido de los datos del diagnóstico contribuya con la planificación de las acciones formativas, que tendrán los profesores de español del municipio como público objetivo.

\footnotetext{
${ }^{1}$ Licenciada em Letras - Português/Espanhol; Universidade Federal do Pampa - campus Jaguarão; Jaguarão, Rio Grande do Sul, Brasil; carolinefeijo@ unipampa.edu.br.

2 Doutora em Educação Física; Universidade Federal do Pampa - campus Jaguarão; Jaguarão, Rio Grande do Sul, Brasil; paulabianchi@unipampa.edu.br.
} 
Palabras claves: Formación continua de profesores; acciones colaborativas; investigación-acción; enseñanza de español.

\begin{abstract}
From the last changes made in the National Education Guidelines and Bases, the Brazilian political-educational vision puts the teaching of Spanish language in schools in an optional manner. In view of this, the state and municipal legislative and executive powers, recognizing the importance of teaching this language in the school curriculum, are proposing local actions to ensure that the discipline of Spanish remains offered as a compulsory one. This is the case of the municipality of Jaguarão-Brasil, bordering Rio Branco-Uruguay, which included §6, in art. 134, of the Municipal Organic Law. In this context, with the intention of strengthening the teaching of Spanish in the Municipality, it is sought, through a master's degree in progress, to establish with the teachers of Spanish of the municipal network of Jaguarão formative and collaborative experiences (NÓVOA, 1992; SCHÖN, 2000), which are aimed at the teaching of this language. This paper aims to discuss the results obtained during the diagnosis of reality. Methodologically, the study is characterized as action research (THIOLLENT, 2009) and uses the following instruments to obtain the data: a) documentary research; b) focus group; and c) questionnaire. It is hoped that the content analysis of the diagnosis data will contribute to the planning of the training actions themselves, which will have the Spanish teachers of the municipality as the target audience.
\end{abstract}

Keywords: Continuing teacher training; collaborative actions; action research; teaching Spanish.

\title{
1. Introdução
}

Passado um ano da aprovação da Lei Federal $n^{\circ} 13.415 / 2017$, que alterou a Lei de Diretrizes e Bases da Educação Nacional (LDB), de 1996, e revogou a Lei no 11.161/2005, que previa a oferta obrigatória do ensino de espanhol nas escolas de todo o Brasil e constituíase como uma ação político-linguística de ampliação do ensino de línguas e culturas estrangeiras nas escolas, encontramo-nos, atualmente, em um intenso cenário de mudanças em todo o país.

Com a reformulação nacional do sistema educativo, foi acrescentado à LDB o art. 35A, cujo parágrafo quarto tornou obrigatório apenas o ensino da língua inglesa e optativo o ensino de outras línguas estrangeiras, dando preferência ao espanhol nos casos em que houver disponibilidade pelos sistemas de ensino.

Como consequência desta alteração, a Base Nacional Comum Curricular (BNCC) não contempla o ensino de língua espanhola em suas etapas. Tanto na etapa do ensino fundamental, já vigente, quanto na proposta referente ao ensino médio, que ainda aguarda homologação, consta apenas o inglês nas competências referentes à área da linguagem.

A partir desta nova visão político-educacional de opcionalidade para o ensino de língua espanhola nas escolas do Brasil, os poderes Legislativos e Executivos estaduais e municipais, reconhecendo a importância do ensino deste idioma no currículo escolar, estão propondo ações locais para fazer com que o componente curricular de espanhol permaneça sendo ofertada como obrigatório. Conforme pesquisa realizada por Feijó-Quadrado e Troian (2018), observou-se que este é o caso do município de Jaguarão-Brasil, fronteiriço com Rio 
Branco-Uruguai, que incluiu o §6, no art. 134, da Lei Orgânica Municipal, introduzindo o ensino de língua espanhola no currículo do ensino fundamental/anos finais (do $6^{\circ}$ ao $9^{\circ}$ ano) e na modalidade Educação de Jovens e Adultos (EJA) da rede municipal.

Em vista destes fatos, que demonstram uma preocupação do Município de Jaguarão em relação ao fortalecimento do ensino do idioma, com a intenção de avançar e contribuir com este processo, torna-se relevante compreender: Como é a formação continuada dos profissionais que estão atuando no componente curricular? Os professores costumam participar de formação continuada na área de espanhol? Estas formações partem do contexto e dos problemas identificados pelos profissionais? São oportunizados momentos de troca de experiências para a proposição de ações colaborativas voltadas à resolução de possíveis situações problemáticas? E, ainda: Quais seriam, na fronteira, as dificuldades e as potencialidades identificadas pelos professores para o ensino de espanhol como língua estrangeira? Estas são algumas questões que motivam a realização deste estudo.

Estes questionamentos deram suporte inicial para o diagnóstico da realidade de uma pesquisa de mestrado em educação em andamento, pela Universidade Federal do Pampa campus Jaguarão. A intenção é estabelecer com os professores de espanhol da rede municipal de Jaguarão experiências formativas e colaborativas voltadas para o ensino deste idioma.

Neste contexto, o objetivo geral deste trabalho é apresentar os resultados colhidos durante a realização do diagnóstico da realidade da pesquisa de mestrado. Como objetivos específicos tem-se: a) verificar se os professores de espanhol vinculados à rede municipal de ensino de Jaguarão realizam formação continuada na área de espanhol; b) identificar se essas formações partem do contexto e dos problemas identificados pelos docentes; c) investigar se são oportunizados momentos de troca de experiências para a proposição de ações colaborativas voltadas à resolução de possíveis situações problemas; e d) descobrir as dificuldades e as potencialidades identificadas pelos professores para o ensino de espanhol como língua estrangeira nas escolas em que atuam.

Metodologicamente, o estudo é qualitativo e caracteriza-se como pesquisa-ação (THIOLLENT, 2009). Utiliza-se das seguintes técnicas para obtenção dos dados: a) pesquisa documental (LÜDKE; ANDRÉ, 2015; b) grupo focal (MICHEL, 2009); e c) questionário (MARKONI, LAKATOS, 2010). O corpus será analisado a partir de uma aproximação da análise de conteúdo proposta por Bardin (2011). A intenção é de que os dados levantados contribuam para o planejamento de ações formativas, que terão os professores de espanhol do município integrados à pesquisa-ação. 
Este estudo justifica-se por possibilitar conhecer a realidade dos docentes no que tange à sua formação continuada, integrá-los à pesquisa-ação para, após, desenvolver as atividades formativas, que têm a finalidade de contribuir com a prática pedagógica dos profissionais envolvidos. Além disso, soma-se a necessidade política de realizar pesquisas que busquem fortalecer o ensino de espanhol, principalmente devido ao atual cenário nacional de enfraquecimento do ensino do idioma nas escolas do Brasil.

Após esta introdução, será expresso o referencial teórico relativo à formação continuada de professores (NÓVOA, 1992; SCHÖN, 2000; IMBERNÓN, 2010; TARDIF, LESSARD, 2008) e a legislação que trata sobre o ensino de espanhol em Jaguarão. Em seguida, será apresentada a metodologia utilizada no diagnóstico da realidade e realizada a análise dos resultados obtidos. Por último, serão discutidas as conclusões e apresentadas as próximas etapas da pesquisa.

\section{A formação continuada de professores e o ensino de espanhol em Jaguarão}

Nesta seção serão evidenciadas as concepções teóricas adotadas sobre formação continuada de professores, com base em Nóvoa (1992), Schön (2000), Imbernón (2010), e Tardif e Lessard (2008). Também será apresentada a legislação municipal que trata sobre o ensino de espanhol nas escolas de Jaguarão. Estes referenciais servirão como base para análise dos dados do diagnóstico, que já integra as fases da pesquisa-ação.

\subsection{Concepções adotadas acerca da formação continuada de professores}

De acordo com Nóvoa (1992, n.p), a formação continuada "deve estimular uma perspectiva crítico-reflexiva, que forneça aos professores um pensamento autónomo e que facilite as dinâmicas de auto-formação participada". Além disso,

[...] a formação não se constrói por acumulação (de cursos, de conhecimentos, ou de técnicas), mas sim através de um trabalho de reflexividade crítica sobre as práticas e de (re)construção permanente de uma identidade pessoal. Por isso é tão importante investir a pessoa e dar um estatuto ao saber da experiência (NÓVOA, 1992, n.p, grifos do autor).

Este saber da experiência, mencionado por Nóvoa (1992), possibilita uma pedagogia interativa e dialógica, que vai além da dimensão pedagógica e atinge um quadro conceitual de produção de saberes. De acordo com o autor, a formação deve perpassar pela “experimentação, pela inovação, pelo ensaio de novos modos de trabalho pedagógico. E por uma reflexão crítica sobre a sua utilização" (NÓVOA, 1992, n.p), atingindo processos de investigação articulados às práticas educativas. 
Somada à importância da mobilização da experiência, também se acredita que, para a formação continuada, o diálogo entre os professores "é fundamental para consolidar saberes emergentes da prática profissional" (NÓVOA, 1992, n.p), estando, “a formação [...] indissociavelmente ligada à 'produção de sentidos' sobre as vivências e sobre as experiências de vida" (FINGER, 1989; BALL \& GOODSON, 1989, apud NÓVOA, 1992, n.p).

Estas perspectivas apresentadas por Nóvoa demonstram quais os aspectos principais a serem considerados para a formação continuada de professores, no entanto, é possível se perguntar: como se deu a produção de conhecimentos na formação de professores?

Imbernón (2010, p. 14) menciona que,

[...] se analisarmos a maioria dos estudos sobre formação continuada, constataremos que essas foram se movendo de uma fase descritiva, com muitos textos sobre a temática, para uma mais experimental [...].

Relata que durante os anos 1980, 1990 e 2000 foram realizados muitos programas de formação continuada, alguns, após análises rigorosas, foram desqualificados, enquanto outros apresentavam "novas propostas e reflexões que podem ajudar a construir o futuro dessa formação" (IMBERNÓN, p. 14).

Como forma de apresentar um resgate para visualizar os avanços da formação continuada, Imbernón (2010, p. 15) divide a genealogia da formação em 4 etapa:

- Até os anos de 1970: início.

- Anos de 1980: paradoxo da formação. O auge da técnica na formação e a resistência prática e crítica.

- Anos de 1990: introdução da mudança, apesar de tímida.

- Anos 2000 até a atualidade: busca de novas alternativas

Embora todas as etapas sejam importantes e perduram ao longo da formação, o autor expõe o seguinte quadro como forma de demonstrar e sistematizar "uma pequena e certamente imprecisa genealogia do conceito de 'conhecimento' e sua relação com a formação, sobre o que se pensa e deseja" (IMBERNÓN, 2010, p. 23): 
RELACult - Revista Latino-Americana de Estudos em Cultura e Sociedade

Revista Latinoamericana de Estudios en Cultura y Sociedad | Latin American Journal of Studies in Culture and Society V. 05, ed. especial, abr., 2019, artigo no 1210| claec.org/relacult |e-ISSN: 2525-7870

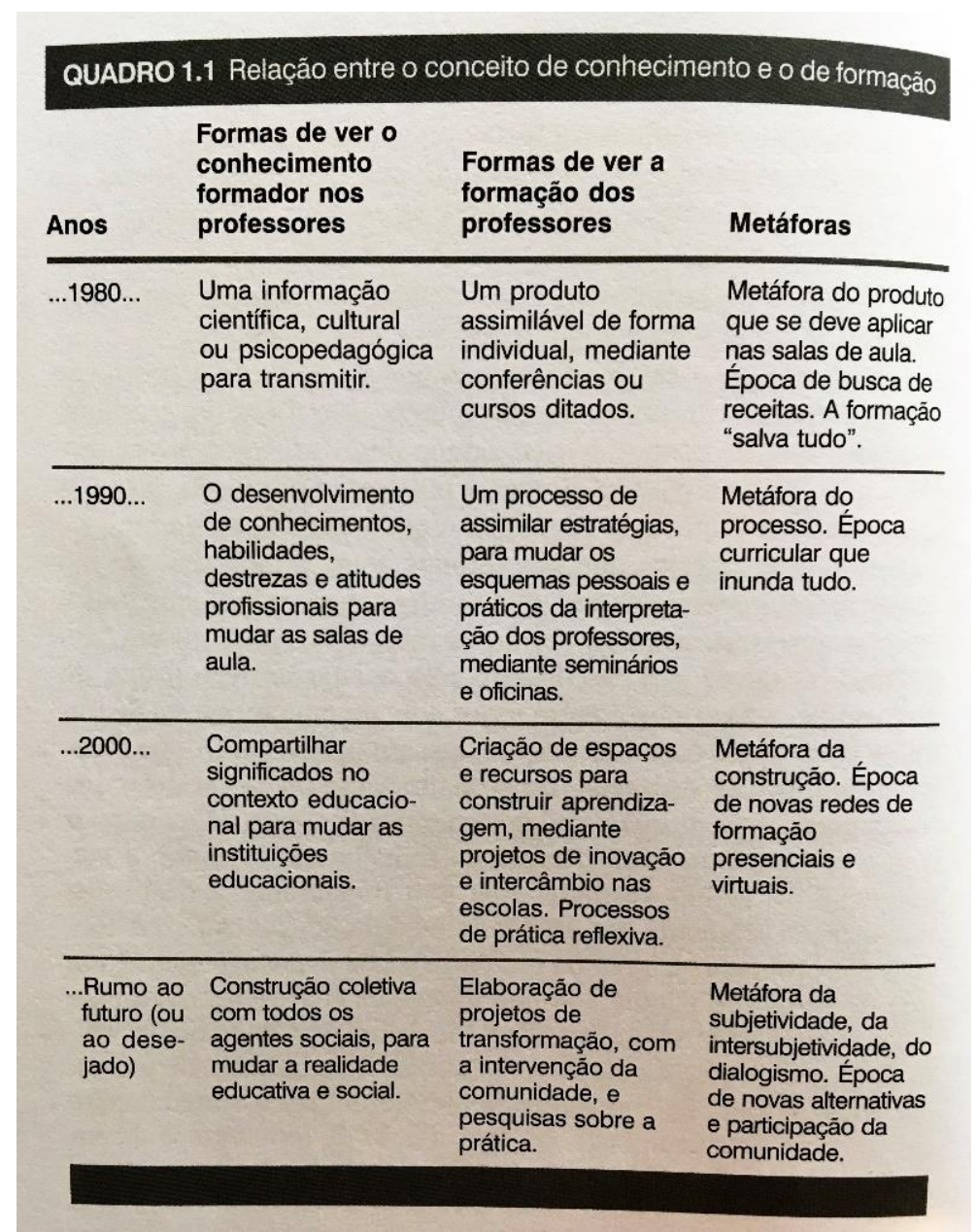

Figura 1: Relação entre o conceito de conhecimento e o de formação

Fonte: Formação continuada de professores (IMBERNÓN, 2010, p. 24)

Percebe-se que entre os anos 1980 e 1990 as formações estavam atreladas ao desenvolvimento individual do professor e tinham características mais conservadoras. Em 1980 o paradigma da racionalidade técnica dominava e não se considerava "que a reflexão e a análise são meios fundamentais para a formação" (IMBERNÓN, 2010, p. 18). Os docentes "foram formados no autoritarismo, com fundo positivista e com uma visão de um ofício no qual haviam soluções teóricas para tudo e para todos” (IMBERNÓN, 2010, p. 19).

Com a institucionalização das formações, as mudanças começaram a aparecer timidamente a partir de 1990. No entanto, esta

[....] institucionalização da formação teve sua parte negativa, já que a formação do professor, historicamente envolvida por uma racionalidade técnica, com uma visão determinista e uniforme [...] potencializou um modelo de treinamento mediante cursos padronizados que ainda perdura (IMBERNÓN, 2010, p. 19).

Este modelo de treinamento citado configurava-se como uma formação continuada e "como um modelo que leva os professores a adquirirem conhecimentos ou habilidades, por 
meio da instrução individual ou grupal que nasce a partir da formação decidida por outros" (IMBERNÓN, 2010, p. 19).

Entratanto, Imbernón (2010, p. 20) menciona que, também na época de 1990, começaram a se desenvolver aspectos positivos, que fomentaram avanços na formação continuada:

[...] a preocupação do âmbito universitário com estudos teóricos, uma consciência maior dos professores comprometidos, que demandavam uma formação na qual os professores estivessem mais implicados, o desenvolvimento de modelos de formação alternativos, como o questionamento da prática mediante projetos de pesquisa-ação, [...] o aparecimento de grande quantidade de textos, traduzidos e locais, com análises teóricas, experiências, comunicações, assim como a celebração de encontros, jornadas, congressos e similares (grifo do autor).

A partir dos anos 2000, as teorias já demonstravam um avanço em direção ao que é estabelecido por Nóvoa, pois “cada vez mais tem importância a formação emocional das pessoas, a relação entre elas, as redes de intercâmbio, a comunidade como elemento importante para a educação" (IMBERNÓN, 2010, p. 22).

A partir da genealogia apresentada, é possível observar que a história da formação continuada de professores, embora demonstre avanços, ainda é de "dependência e subsídio" (IMBERNÓN, 2010, p. 81). A consequência desse tipo de atuação fez dos professores objetos da formação. De acordo com Imbernón (2010, p. 81), "a mudança, no futuro da formação continuada, passa pela atitude dos professores de assumirem a condição de serem sujeitos da formação, intersujeitos com seus colegas [...]" e não um instrumento de outros.

Assim, Imbernón (2010, p. 112) estabelece que o papel da formação continuada é “criar espaços nos quais o professor tenha voz, seja escutado e desenvolva processos reflexivos e questionadores sobre os processos educacionais [...]”. Também é importante que a formação parta de situações problemáticas identificadas pelos docentes, já que "na realidade dos professores, não há tantos problemas genéricos, senão muitas situações problemáticas que ocorrem em contextos sociais e educacionais determinados" (IMBERNÓN, 2010, p. 54).

Além disso, o autor também menciona a necessidade de estabelecer uma cultura colaborativa como princípio e como metodologia na formação de professores. Para isto, destaca que é necessário:

$>$ Romper com o individualismo da formação.

> Considerar a colaboração como colegialidade e também mais como ideologia do que como estratégia de gestão.

$>$ Não entender colaboração como uma tecnologia que se ensina, mas como um processo de participação, implicação, apropriação e pertencimento.

$>\mathrm{Na}$ colaboração partir do respeito e do reconhecimento do poder e da capacidade de todos os professores. 
Dedefinir e ampliar a liderança escolar, o que representa uma necessidade.

$>$ Poderão ajudar na formação colaborativa: a pesquisa-ação, a elaboração de projetos de mudança e a narração. (IMBERNÓN, 2010, p. 72)

A busca de novas perspectivas acerca da formação continuada não deve apenas aproximá-la ao contexto de atuação docente, mas sim, potencializar "uma nova cultura formadora, que gere novos processos na teoria e na prática da formação, introduzindo-nos em novas perspectivas e metodologias" (IMBERNÓN, 2010, p. 40). Como exemplo disso, menciona-se a importância de ações que potencializem as relações entre os professores e a "crença ou autocrença da capacidade de gerar conhecimento pedagógico nos próprios cursos de formação [...] com colegas de trabalho [...], a possibilidade de autoformação, o trabalho em equipe e a comunicação com os colegas” (IMBERNÓN, 2010, p. 40).

Este processo de desenvolvimento da comunicação entre os colegas e da consciência da crença ou autocrença da capacidade em gerar conhecimentos é fundamental para superar as formações estritamente técnicas, já que a profissão docente escapa desta racionalidade por estar inserida em um cenário complexo (IMBERNÓN, 2010, p. 100), cujas situações problemáticas presentes no cotidiano não aparecem apenas de forma instrumental, mas exigem do professor um talento artístico profissional (SCHÖN, 2000).

De acordo com Schön (2000, p. 27), o talento artístico profissional refere-se "aos tipos de competência que os profissionais demonstram em certas situações da prática que são únicas, incertas e conflituosas". Ainda de acordo com o autor,

[...] não é por acaso que os professores freqüentemente se referem a uma "arte" do ensino ou da administração e usam o termo artista para referir-se a profissionais especialmente aptos a lidar com situações de incerteza, singularidade e conflito (SCHÖN, 2000, p. 24).

Schön (2000, p. 25) propõe que deveríamos "estudar a experiência de aprender por meio do fazer" e propõe o triplo movimento do conhecer-na-ação; reflexão-na-ação e refletir sobre a reflexão-na-ação. Estes conceitos, acrescidos às características apresentadas por Nóvoa e Imbernón, demonstram a importância do processo formativo a partir do que Imbernón (2010, p. 41) chama de "rearmada moral, intelectual e profissional dos professores" com a intenção de torná-los "protagonistas ativos de sua formação em seu contexto de trabalho" (IMBERNÓN, 2010, p. 41).

Dito tudo isto, ainda é importante somar a estas concepções a necessidade de considerar a profissionalização do ensino como um trabalho docente, conforme estabelecem Tardif e Lessard (2011). Além disso, a formação continuada dos professores não pode estar 
distanciada das políticas que incidem sobre os docentes. De acordo com Imbernón (2010, p. 45), para que a formação seja viva e dinâmica, é indispensável uni-la à carreira profissional ou ao "estatuto da função docente que inclua incentivos profissionais e promoções [...] que recompense ou, ao menos, não castigue aqueles que se dedicam [...] não apenas de forma individual, mas, também, coletivamente". A intenção da formação "deveria fomentar o desenvolvimento pessoal, profissional e institucional dos professores, potencializando um trabalho colaborativo para transformar a prática" (IMBERNÓN, 2010, p. 45).

Considerando o que foi apresentado neste referencial, a perspectiva do projeto de mestrado em andamento é propor uma formação continuada em que os professores de espanhol atuem como sujeitos ativos, identificando conjuntamente situações problemáticas presentes no ensino do idioma, planejando ações para superá-las, a fim de chegar a um trabalho colaborativo (IMBERNÓN, 2010), que vise o engajamento e reflexão para o saber advindo da experiência e da experimentação, ensaiando novos modos de trabalho e propondo uma reflexão sobre eles (NÓVOA, 1992). Por tudo isto é que o projeto se caracteriza como pesquisa-ação (THIOLLENT, 2009).

Na próxima seção, para fundamentar e contextualizar o leitor acerca do atual cenário legal em relação ao ensino de espanhol em Jaguarão, cidade em que o estudo está sendo realizado, será apresentada a alteração realizada, em 2018, na Lei Orgânica Municipal, que torna obrigatório o ensino de espanhol na rede municipal de ensino.

\subsection{A Lei orgânica municipal e o ensino de espanhol em Jaguarão}

A opcionalidade para o ensino de espanhol nas escolas do Brasil, resultado das alterações realizadas, em 2017, na Lei de Diretrizes e Bases da Educação Nacional (LDB), desencadeou diversos movimentos que tinham a intenção de reverter este cenário causado pelo governo federal, e tornar o ensino do idioma obrigatório a partir de legislações estaduais e municipais.

Em Jaguarão, cidade fronteiriça com o município uruguaio de Rio Branco, os movimentos iniciais partiram de um grupo de professores do curso de Letras - Português e espanhol, da Universidade Federal do Pampa, que estavam integrados ao movimento estadual cunhado como \#FicaEspanhol. A intenção era buscar o apoio do legislativo para tornar o ensino de espanhol obrigatório nas escolas municipais, já que, a nível estadual, estava tramitando o Projeto de Emenda Constitucional (PEC) 270/2018, promulgado em 21/12/2018.

Após reuniões entre vereadores, os membros do movimento \#FicaEspanhol e a comunidade, foram encaminhados debates para fomentar a discussão sobre a temática e criar 
políticas públicas que possibilitassem a manutenção da oferta da disciplina como obrigatória nas escolas. O resultado destas ações foi a aprovação, em outubro de 2018, da Emenda à Lei Orgânica Municipal n 20.

Através da inclusão do §6 ao art. 134 da Lei Orgânica, a Emenda 20/2018 tornou obrigatório o ensino de língua espanhola nas escolas municipais de Jaguarão, com vigência a partir de 2019.

$\S 6^{\circ}$ - O ensino de língua espanhola será introduzido na rede municipal de ensino, no currículo do ensino fundamental/anos finais (do $6^{\circ}$ ao $9^{\circ}$ ano) e na modalidade Educação de Jovens e Adultos (EJA).

A partir destas alterações, é possível reconhecer um compromisso políticoeducacional assumido pelo Legislativo em relação à oferta obrigatória de espanhol nos anos finais e, ainda, um compromisso com uma política educacional e linguística plurilíngue, bem como com o "derecho de enseñar y aprender español en las escuelas fronterizas brasileñas" (ZWARG; ARF; BARREDA, 2018, p. 96).

Apresentadas as perspectivas teóricas sobre formação continuada de professores, bem como a legislação municipal que trata sobre a obrigatoriedade do ensino de espanhol em Jaguarão, na próxima seção, serão evidenciados os caminhos metodológicos escolhidos para a realização deste estudo.

\section{Caminhos metodológicos}

Metodologicamente, o estudo é qualitativo e caracteriza-se como pesquisa-ação (THIOLLENT, 2009) por considerar que, de acordo com Imbernón (2010, p. 9), a formação continuada de professores deve partir de processos de pesquisa-ação, com a participação ativa e autônoma dos docentes envolvidos, considerando o contexto de trabalho.

A pesquisa qualitativa "preocupa-se [...] com aspectos da realidade que não podem ser quantificados, centrando-se na compreensão e explicação da dinâmica das relações sociais" (SILVEIRA; CÓRDOBA, 2009, p. 32). Já a pesquisa-ação é

[...] um tipo de pesquisa social com base empírica que é concebida e realizada em estreita associação com uma ação ou com a resolução de um problema coletivo e no qual os participantes representativos da situação ou do problema estão envolvidos de modo cooperativo ou participativo (THIOLLENT, 2009, p. 16).

$\mathrm{Na}$ pesquisa-ação os participantes atuam ativamente "no equacionamento dos problemas encontrados, no acompanhamento e na avaliação das ações desencadeadas em função dos problemas" (THIOLLENT, 2009, p. 17). Através desta metodologia, "é possível estudar dinamicamente os problemas, decisões, ações negociações, conflitos e tomadas de 
consciência que ocorrem entre os agentes durante o processo de transformação da situação" (THIOLLENT, 2009, p. 21).

A pesquisa-ação definida como método, "contém diversos métodos ou técnicas particulares em cada fase ou operação do processo de investigação" (THIOLLENT, 2009, p. 29). Neste estudo, os dados obtidos através do diagnóstico da realidade integram a fase $1 \mathrm{da}$ pesquisa de mestrado em andamento, utilizando-se das seguintes técnicas: a) pesquisa documental (LÜDKE; ANDRÉ, 2015); b) grupo focal (MICHEL, 2009); e c) questionário (MARKONI, LAKATOS, 2010).

De acordo com Marconi e Lakatos (2010, p. 157), a pesquisa documental caracterizase pela "[...] coleta de dados [...] restrita a documentos, escritos ou não [...]". Ainda de acordo com as autoras, os documentos oficiais "constituem geralmente a fonte mais fidedigna de dados" (MARCONI; LAKATOS, 2010, p. 161).

Para a pesquisa documental, enviou-se dois ofícios ao Departamento Pedagógico da Secretaria Municipal de Educação e Desporto (SMED). O primeiro, solicitava as seguintes informações: a) Quais escolas ofertam espanhol do sexto ao nono ano? Quais escolas ofertam do sexto ao sétimo? E quais ofertam do oitavo ao nono? b) Qual a formação inicial dos professores que atuam nas disciplinas de espanhol? c) Qual o concurso que realizaram? Algum foi nomeado para atuar exclusivamente na disciplina de espanhol? d) Em relação a capacitação dos professores em atividade, alguma esteve voltada ao espanhol?

O segundo ofício solicitava à SMED o envio do Plano Municipal de Educação para fins de estudo, pois, após uma pesquisa no site da Prefeitura Municipal de Jaguarão e da Câmara de Vereadores, não se encontrou o documento.

Após a resposta do pedido de informação e o envio do Plano Municipal de Educação pela SMED, buscou-se nestes documentos informações referentes às políticas municipais voltadas à formação continuada de professores.

Após a pesquisa documental, realizou-se o grupo focal, considerado como "uma técnica que pode ser utilizada em todas as fases de investigação, nas quais se pretenda obter informações sobre o clima, as expectativas, os problemas e conflitos não claros, explicitados" (MICHEL, 2009, p. 96).

Como primeira etapa para a realização do grupo focal, foi-se até a SMED para apresentar a pesquisa de mestrado em andamento. Solicitou-se apoio para a realização do diagnóstico da realidade e o envio de convite aos professores de espanhol para participação na atividade. $\mathrm{O}$ grupo focal tinha a intenção de descobrir quais as potencialidades e dificuldades identificadas pelos professores para o ensino de espanhol no município; propiciar um 
momento de troca de experiências entre os profissionais; contribuir para a elaboração de uma proposta de formação continuada a partir do contexto de atuação e, ainda, engajar os professores à pesquisa-ação.

A atividade foi realizada na Biblioteca Pública de Jaguarão e durou cerca de uma hora e trinta minutos. Foram convidados os oito professores vinculados a rede municipal de ensino, que atuam no componente de curricular de espanhol. Quatro professoras fizeram-se presentes. A atividade foi conduzida pela pesquisadora, e contou com a participação das coordenadoras do departamento pedagógico da SMED. As questões norteadoras do grupo foram: 1) Potencialidades para o ensino de espanhol na fronteira; 2) Dificuldades para o ensino de espanhol na fronteira; 3) Metodologias de ensino utilizadas (uso da TICs, por exemplo); 4) Ensino de espanhol extra-classe - promoção e incentivo; 5) Formação continuada dos professores (Como os professores se formam e informam? Qual a frequência da formação? Qual o foco dessas formações? Qual a duração? São formações pagas ou gratuitas?); 6) Temas de interesse para ações de formação continuada na área do espanhol; 7) Na sua opinião como deveria estar organizada a formação continuada na área de espanhol?; 8) Prefere curso de formação mais teórico, mais prático ou que mescle teoria e prática?

No mesmo dia da realização do grupo focal, solicitou-se às professoras presentes que respondessem a um questionário composto por questões abertas e fechadas. De acordo com Markoni e Lakatos (2010), o questionário é um instrumento que se constitui por perguntas, e que dever ser respondido pelos participantes sem a presença do pesquisador. A intenção do questionário foi identificar a área do concurso; a formação; o tempo de atuação no magistério e na disciplina de espanhol; e as disciplinas em que as docentes atuam, além de complementar as informações obtidas em relação à participação em atividades de formação continuada.

O corpus será analisado a partir de uma aproximação à análise de conteúdo proposta por Bardin (2011, p. 48), definida como

Um conjunto de técnicas de análise das comunicações visando obter por procedimentos sistemáticos e objetivos de descrição de conteúdo das mensagens indicadores (quantitativos ou não) que permitam a inferência de conhecimentos relativos às condições de produção/recepção (variáveis inferidas) dessas mensagens (BARDIN, 2011, p. 48, grifo da autora).

Após a descrição dos caminhos metodológicos deste estudo, prosseguiremos, na próxima seção, com a análise dos dados obtidos a partir do diagnóstico da realidade, que integra a fase um da pesquisa-ação.

\section{Análise do corpus}


Esta seção apresenta os resultados dos dados obtidos através da pesquisa documental; do grupo focal; e do questionário. Analisar-se-á a resposta do departamento pedagógico da Secretaria Municipal de Educação e Desporto (SMED) ao ofício que solicita informações sobre os professores de espanhol; o Plano Municipal de Educação (PME); as informações obtidas através do grupo focal; e as respostas ao questionário. Todos estes dados compõe o corpus deste estudo, que integra a fase um da pesquisa de mestrado em andamento, cuja intenção é realizar uma formação continuada colaborativa, através de uma pesquisa-ação.

\subsection{A formação continuada de professores e o PME de Jaguarão}

Através da resposta ao pedido de informação, o Departamento Pedagógico da SMED não mencionou nenhuma formação continuada realizada na área de espanhol. Após este dado, fez-se a análise do PME para verificar informações referentes às políticas municipais voltadas à formação continuada de professores. No documento, identificou-se, a subseção 4.11 Formação e valorização dos profissionais em educação - metas e estratégias, presente na seção 4 Diagnóstico, Metas e Estratégias por níveis de ensino, modalidade e temáticas. A subseção 4.11 apresenta, em primeiro momento, um diagnóstico com o número de professores e o percentual de formação, após estabelece 4 metas para a formação de professores que, de acordo com o documento, devem ser cumpridas no prazo de 10 anos, tempo de vigência do PME, publicado em 2015.

Inicialmente, como forma de contextualização, o PME (2015, p. 57) menciona que a rede municipal conta 370 profissionais atuando nas escolas e com 57 aposentados. Dos profissionais em exercício, o documento menciona que apenas $6,76 \%$ não possui graduação. Além disso, destaca que é crescente o número de professores que estão realizando mestrado e doutorado. O quadro abaixo é apresentado para sistematizar as informações:

Tabela 1: Dados do nível de escolaridade dos professores em exercício

\begin{tabular}{|l|l|}
\hline Nível de escolaridade dos professores em exercício & \\
\hline Quadro em Extinção - Sem concurso & 06 \\
\hline Ensino Médio/ magistério & 19 \\
\hline Ensino Superior Licenciatura Plena & 130 \\
\hline Ensino Superior Licenciatura Curta & 01 \\
\hline Pós graduação - Especialização & 211 \\
\hline
\end{tabular}


RELACult - Revista Latino-Americana de Estudos em Cultura e Sociedade

\begin{tabular}{|l|l|} 
Mestrado e Doutorado & 03 \\
\hline Total & 370 \\
\hline
\end{tabular}

Fonte: PME, 2015, p. 58

A partir dos dados apresentados, o $\operatorname{PME~(2015,~p.~58)~estabelece~que~deverão~ser~}$ ponderadas questões relativas à: "valorização salarial; condições adequadas de trabalho nas escolas, formação continuada como meio de aprimoramento da práxis pedagógica e manutenção do Plano de Carreira do Magistério”. Assim, apresenta as metas 15, 16, 17 e 18:

Meta 15: Implantar o Sistema Municipal de Formação e de Valorização dos Profissionais da Educação, no prazo de 1 (um) ano a partir da aprovação desse PME, assegurando que todos os professores da educação básica possuam formação específica de nível superior, obtida em curso de licenciatura na área de conhecimento em que atuam, até o último ano de vigência desse Plano (PME, 2015, p. 59).

Meta 16: Formar, em nível de pós-graduação, $80 \%$ (oitenta por cento) dos professores e professoras da educação básica, até o último ano de vigência deste PME, e garantir a todos/as os/as profissionais da educação básica formação continuada em sua área de atuação, considerando as necessidades, demandas e contextos dos sistemas de ensino (PME, 2015, p. 61).

Meta 17: Valorizar o magistério público da educação básica, a fim de igualar o rendimento médio dos profissionais do magistério ao dos demais profissionais com escolaridade equivalente, até o final do sexto ano de vigência deste PME (PME, 2015, p. 62).

Meta 18: Assegurar, no prazo de 2 (dois) anos a partir da aprovação do PME, a existência de planos de Carreira para os/as profissionais da educação básica, tomando como referência o piso salarial nacional profissional, definido em lei federal, nos termos do inciso VIII do art. 206 da Constituição Federal (PME, 2015, p. 63).

A partir da análise das metas estabelecidas, bem como das estratégias mencionadas para atingir cada uma delas, verifica-se que o foco do Município está voltado principalmente às questões relativas à formação inicial dos professores, bem como à valorização salarial.

As metas 15 e 16 apresentam as seguintes estratégias que perpassam por critérios de formação continuada para:

Implementar [...] políticas construídas em regime de colaboração com as instituições de ensino superior, para a oferta de cursos presenciais e programas especiais gratuitos e preferencialmente públicos, que assegurem formação inicial e continuada aos docentes em efetivo exercício;

Assegurar [...] o foco na formação do profissional, a partir de referenciais curriculares, que articulem a carga horária dos fundamentos constituintes das ciências da educação, com a parte especializada das áreas de conhecimento e a formação para a pesquisa pedagógica [...] 
Programar, sob responsabilidade da SMED, a partir do primeiro ano de vigência do PME, projetos específicos de formação continuada, para os profissionais da educação que atuam com as populações do campo, comunidades quilombolas, populações itinerantes e populações privadas de liberdade [...]

Promover periodicamente, sob coordenação da SMED, o debate público com as instituições de ensino superior sobre as organizações curriculares dos cursos de licenciatura, na busca pela renovação pedagógica com foco no aprendizado, com carga horária em formação geral, com formação nas áreas do conhecimento e didáticas específicas, incorporando tecnologias da informação e da comunicação e enfatizando as diretrizes curriculares para a educação básica;

Assegurar, na formação continuada dos profissionais da educação básica, conteúdos referentes às temáticas da inclusão de pessoas com deficiências, transtornos globais do desenvolvimento, e altas habilidades ou superdotação; (PME, 2015, p. 59-61).

Assegurar aos professores [...] tempo específico para estudos e planejamentos, estabelecendo condições efetivas para o desenvolvimento de pesquisas e projetos acadêmicos e pedagógicos, que garantam a formação contínua [...] (PME, 2015, p. 61)

Neste sentido, a partir do que foi apresentado aqui, nota-se que é premissa realizar ações de formação continuada voltadas, entre outras questões, às "áreas do conhecimento e didáticas específicas, incorporando tecnologias da informação e da comunicação" (PME, 2015, p. 61). No entanto, o documento não menciona como deve ser compartilhado o conhecimento nos processos de ação. Também não enfatiza à importância de ações colaborativas (IMBERNÓN, 2010), com foco na experimentação e na vivência e experiência dos professores para a transformação da prática (NÓVOA, 1992). Neste sentido, considera-se que ainda é necessário tratar sobre estas questões para avançar no que tange ao trabalho docente.

No entanto, como menciona Imbernón (2010, além da formação continuada, também é necessário investir na carreira docente e, neste ponto, as estratégias propostas no PME demonstram um avanço inicial, embora trate especificamente ao docente de forma individual, necessitando buscar ações que incentivem a promoção e a valorização de atividades colaborativas.

Por outro lado, é possível questionar: será que o concurso realizado pelos professores permite que eles atuem apenas em suas áreas de formação? Será que ter $80 \%$ dos professores com pós-graduação garante que o curso realizado tenha sido na área específica de atuação? Além disso, será que existe identificação por parte dos docentes com as áreas em que atuam?

Uma pequena amostra para responder estas questões estará presente na próxima seção, que apresentará os dados obtidos através do questionário e do grupo focal realizado com os professores de espanhol da rede municipal de Jaguarão. 


\subsection{O questionário e a identificação dos sujeitos}

Escolheu-se o questionário como instrumento de identificação dos sujeitos devido sua vantagem para a tabulação dos dados e para complementar as informações obtidas através do grupo focal. Além disso, através do questionário, foi expresso o interesse das quatro professoras em se integrar à pesquisa-ação e participar de uma formação continuada na área de espanhol, de cunho colaborativo, em que eles serão os atores do processo, definindo o tema, planejando as ações, interagindo, vivendo experiências e refletindo sobre o processo.

De um total de oito profissionais que atuam no componente curricular de espanhol na rede municipal de educação de Jaguarão, participaram do encontro quatro professoras. Neste estudo, a identificação dos sujeitos, tanto do questionário, quanto do grupo focal, será realizada da seguinte maneira: Professora A; Professora B; Professora C; e Professora D.

Como o município é relativamente pequeno, tendo apenas 8 escolas com ensino fundamental na rede municipal, optamos por não mencionar a qual instituição cada docente é vinculado, já que esta informação não contribuirá diretamente com os objetivos da pesquisa, apenas destacamos que as docentes pertenciam às seguintes escolas: Escola Municipal de Ensino Fundamental Fernando Corrêa Ribas; Escola Municipal de Ensino Fundamental Marcílio Dias; Escola Municipal de Educação Básica Lauro Ribeiro; e Escola Municipal de Ensino Fundamental Ceni Soares Dias.

Como resultado, a partir das respostas dadas pelas professoras, apresenta-se a seguinte tabela, que objetiva contribuir para que o leitor tenha uma visão sistemática do perfil de cada uma das profissionais que responderam ao questionário, participaram do grupo focal e integraram-se à pesquisa-ação.

Tabela 2: Identificação dos sujeitos

\begin{tabular}{|c|c|c|c|c|c|c|c|c|}
\hline Professor & $\begin{array}{c}\text { Área do } \\
\text { concurso }\end{array}$ & $\begin{array}{l}\text { Formação } \\
\text { acadêmica }\end{array}$ & $\begin{array}{l}\text { Formação } \\
\text { continuada }\end{array}$ & $\begin{array}{l}\text { Tempo de } \\
\text { atuação no } \\
\text { magistério } \\
\text { (em anos) }\end{array}$ & $\begin{array}{c}\text { Tempo de } \\
\text { atuação } \\
\text { em } \\
\text { espanhol } \\
\text { (em anos) }\end{array}$ & $\begin{array}{c}\text { CH de } \\
\text { espanhol }\end{array}$ & $\begin{array}{l}\text { Anos/ } \\
\text { séries }\end{array}$ & $\begin{array}{l}\text { Disciplinas } \\
\text { que atua }\end{array}$ \\
\hline A & Séries iniciais & $\begin{array}{c}\text { Magistério; } \\
\text { Graduação: } \\
\text { Letras; Esp. } \\
\text { : Leitura e } \\
\text { Produção } \\
\text { textual }\end{array}$ & Não & 7 & 3 & 3 períodos & 6 e 7 & $\begin{array}{l}\text { Português; } \\
\text { espanhol; } \\
\text { artes e } \\
\text { ciências }\end{array}$ \\
\hline B & Letras/Espanhol & $\begin{array}{c}\text { Graduação: } \\
\text { Letras } \\
\text { Port./Esp. ; } \\
\text { Esp. : } \\
\text { Produção } \\
\text { textual }\end{array}$ & Não & 26 & 17 & 4 períodos & 6 ao 9 & Espanhol \\
\hline
\end{tabular}


RELACult - Revista Latino-Americana de Estudos em Cultura e Sociedade

\begin{tabular}{|c|l|c|c|c|c|c|c|c|}
\hline $\mathrm{C}$ & Espanhol & $\begin{array}{c}\text { Magistério } \\
\text { (Uy) }\end{array}$ & $\begin{array}{c}\text { Palestras; } \\
\text { eventos; } \\
\text { PIBID, etc }\end{array}$ & 16 & 16 & 3 períodos & *não \\
mencionou & $\begin{array}{l}\text { Espanhol e } \\
\text { artes }\end{array}$ \\
\hline $\mathrm{D}$ & Séries iniciais & $\begin{array}{c}\text { Graduação: } \\
\text { Letras } \\
\text { Port./Esp.; } \\
\text { Mestrado: } \\
\text { Profissional } \\
\text { em } \\
\text { Educação }\end{array}$ & $*$ em branco & 29 & 2 & 3 períodos & 6 e 7 & $\begin{array}{l}\text { Espanhol e } \\
\text { português }\end{array}$ \\
\hline
\end{tabular}

Fonte: Autor

Pelas informações, apenas as professoras B e C realizaram concurso para atuar com espanhol, as professoras A e D foram nomeados para atuar nas séries iniciais e, conforme será melhor evidenciado na próxima seção, mencionaram, no grupo focal, que não se identificam com a disciplina.

Das quatro profissionais, apenas a Professora $\mathrm{C}$ mencionou já ter realizado formação continuada na área, através de palestras, eventos e da participação como supervisora do Programa Institucional de Bolsas de Iniciação à docência - PIBID. Além disso, das quatro, apenas a Professora B atua somente na disciplina de espanhol, as demais atuam em outros componentes, inclusive fora da área de formação.

Se for realizada uma análise da formação inicial das docentes, em consonância ao Plano Municipal de Educação, ter-se-á um dado bastante positivo. Das quatro profissionais, todas têm habilitação na área, e 75\% têm pós-graduação. No entanto, duas prestaram concurso para atuar nas séries iniciais e não especificamente em espanhol. Além disso, os cursos de especialização não estão diretamente relacionados ao ensino de língua estrangeira.

Estas informações nos mostram que, para além de incentivar à formação inicial e continuada, também se deve considerar as questões relativas aos concursos prestados e às áreas de identificação dos profissionais. $\mathrm{Na}$ próxima seção, iremos aprofundar estas discussões, a partir dos dados obtidos através do grupo focal.

\subsection{Grupo focal: engajando as professoras à pesquisa-ação}

Como já mencionado na metodologia, a intenção do grupo focal era descobrir quais as potencialidades e dificuldades identificadas pelas professoras para o ensino de espanhol no município; propiciar um momento de troca de experiências entre as profissionais; contribuir para a elaboração de uma proposta de formação continuada a partir do contexto de atuação e, ainda, engajar as docentes à pesquisa-ação. 
O grupo focal desenvolveu-se da seguinte maneira: apresentação da pesquisadora e das professoras, explanação sobre a intenção e os objetivos do encontro; e discussões acerca das questões norteadoras. Na apresentação, cada professora mencionou o nome e a escola de atuação; após, a pesquisadora mencionou o atual cenário em relação ao ensino de espanhol no país e na cidade, destacando a importância de fortalecer o ensino do idioma, mencionou os objetivos do encontro e conduziu as questões norteadoras. Na etapa de discussões sobre as questões norteadoras, as professoras já haviam relatado ter interesse em participar de uma formação continuada colaborativa na área de espanhol e integrar-se à pesquisa-ação.

Como resultados, das quatro profissionais, apenas as professoras B e C mencionaram se identificar com a área. As professoras A e D frisaram que só estavam atuando no componente de espanhol devido à falta de profissionais com habilitação específica, mencionaram ter dificuldades em utilizar o idioma e em planejar as aulas, destacando que, na maioria das vezes, seguem o livro didático, utilizando-o como apoio devido à falta de tempo para buscar outros materiais. Esta dificuldade para o planejamento das aulas devido à falta de tempo foi destacada pelas quatro profissionais, que relatam ter uma carga horária grande, somada à outras atividades burocráticas da escola.

Destaca-se que este momento foi muito importante para observar a interação entre os profissionais, pois eles compartilharam suas metodologias de trabalho, e relataram as dificuldades encontradas para o ensino da língua. A professora $\mathrm{C}$, que tem o espanhol como língua materna e realizou formações continuadas na área, aproveito a oportunidade para compartilhar algumas de suas experiências no ensino do idioma. Mencionou que utiliza o livro didático apenas para algumas atividades, pois a maioria utiliza o espanhol da Espanha, que está distante da realidade dos alunos, que têm a possibilidade de contato com o espanhol rioplatense. Por este motivo, a docente menciona que prefere buscar atividades que façam com que os alunos tenham contato real com a língua, através de intercâmbios com escolas de Rio Branco, ou de atividades usando vídeos e músicas. Estas sugestões estimularam o interesse dos outros colegas, que faziam perguntas e anotações em relação ao que a professora C falava.

Após diversas reflexões, as professoras destacaram a importância daquela primeira oportunidade de troca de experiências. Também entraram em consenso definindo que a falta de material didático era a principal dificuldade para o ensino de espanhol nas escolas. Além disso, mencionaram interesse em participar de formações colaborativas de cunho prático, voltadas para o uso de recursos digitais nas aulas de espanhol, e sugeriram a criação de um acervo com materiais didáticos partindo dos temas propostos no currículo. 
Na sequência, sugeriram a realização de um próximo encontro para compartilhar os materiais que costumavam trabalhar. Definiu-se a data para o segundo encontro, que seria o último antes das ações formativas. A pesquisadora sugeriu que, além do compartilhamento dos materiais usados, o segundo encontro fosse aproveitado para realizar o planejamento da formação. As professoras propuseram que o planejamento inicial fosse feito pela pesquisadora e compartilhado com elas para complementação e sugestões.

As informações desta seção permitiram identificar que o grupo focal atingiu seus objetivos, identificando as principais dificuldades encontradas pelas professoras, proporcionando um momento de trocas de experiências e integrando as profissionais à pesquisa-ação.

\section{Conclusão}

A partir do que foi apresentado neste texto, através da análise documental do PME (2015) e da resposta da SMED ao pedido de informação enviado, foi possível observar que o foco do Município está voltado principalmente às questões relativas à formação inicial dos professores, bem como à valorização salarial e ao plano de carreira. Além disso, a SMED relata não ter informações relativas à formação continuada desenvolvidas especificamente para os professores de espanhol. Ainda no que tange à formação continuada, o PME não menciona como deve ser compartilhado o conhecimento nos processos de ação e não enfatiza à importância de ações colaborativas (IMBERNÓN, 2010), com foco na experimentação e na vivência e experiência dos professores para a transformação da prática (NÓVOA, 1992). Neste sentido, considera-se que ainda é necessário tratar sobre estas questões para avançar em direção à qualificação do trabalho docente.

Com base na análise do questionário, identificou-se o perfil das quatro professoras de espanhol que se integraram à pesquisa-ação. Pelas informações, apenas as professoras $\mathrm{B}$ e C realizaram concurso para atuar com espanhol. As professoras A e D foram nomeados para atuar nas séries iniciais e mencionaram não se identificar com a disciplina. Das quatro profissionais, apenas a Professora $\mathrm{C}$ mencionou já ter realizado formação continuada na área, através de palestras, eventos e da participação como supervisora do Programa Institucional de Bolsas de Iniciação à docência - PIBID. Além disso, das quatro, apenas a Professora B atua somente na disciplina de espanhol, as demais atuam em outros componentes, inclusive fora da área de formação.

Já no grupo focal, foi possível proporcionar um momento de troca de experiências e integrar as profissionais à pesquisa-ação. Identificou-se que as principais dificuldades das 
professoras estão relacionadas à falta de material didático para o ensino de espanhol em sala de aula. Também se percebeu a necessidade de ações que possibilitem que elas usem a língua espanhola em situações reais de comunicação.

Como conclusão, a partir dos dados obtidos, embora duas das quatro professoras não se identifiquem com o espanhol, todas têm intenção em realizar formação continuada na área. Em consenso, definiram que suas principais dificuldades para o ensino de espanhol estão voltadas à obtenção de materiais didáticos. Além disso, as profissionais destacaram a importância da oportunidade e do momento de troca de experiência entre elas. Esse dado indica à gestão do município um dos caminhos a ser seguido no que tange à formação continuada dos professores. Também contribui com informações que darão base à pesquisa de mestrado em andamento, que tem a intenção de estabelecer com os professores de espanhol da rede municipal de Jaguarão experiências formativas e colaborativas voltadas para o ensino e o uso da língua.

Neste sentido, para concluir este estudo, considera-se importante mencionar quais serão as próximas etapas da pesquisa-ação:

Fase 2: Descobrindo o conceito de formação continuada para os professores e planejando a ação formativa;

Fase 3: "Integración" e "Mais espanhol": Um relato sobre os Projetos de extensão realizados pelo campus Jaguarão da Unipampa;

Fase 4: A formação colaborativa;

Fase 5: Avaliação e divulgação da ação; e revisão do conceito de formação continuada.

\section{Referências}

FEIJÓ-QUADRADO, Caroline Gonçalves; TROIAN, Alessandra. $O$ ensino de espanhol na fronteira de Jaguarão/BR e Rio Branco/UY: análise dos limites e perspectivas educacionais após a revogação Lei $\mathrm{n}^{\mathrm{o}}$ 11.161/2005. 2018. 17 f. Trabalho de conclusão de curso (Especialização em Gestão Pública Municipal) - Universidade Federal do Pampa, Hulha Negra, 2018

MARCONI, Marina de Andrade; LAKATOS, Eva Maria. Fundamentos de metodologia científica. 7 ed. São Paulo: Atlas, 2010.

NÓVOA, António. A formação de professores e profissão docente. In: Os professores e a sua formação. Lisboa: Dom Quixote, 1992. p. 13-33. Disponível em: http://repositorio.ul.pt/handle/10451/4758. Acesso em: $27 \mathrm{dez} .2018$.

SCHÖN, Donald A. Educando o profissional reflexivo: um novo desing para o ensino e a aprendizagem. Tradução de Roberto Cataldo Costa. Porto Alegre: Artmed, 2000. 
SILVEIRA, Denise Tolfo; CÓRDOBA, Fernanda Peixoto. Unidade 2: A pesquisa científica. In: GERHARDT, Tatiana Engel; SILVEIRA, Denise Tolfo. Métodos de pesquisa. Porto Alegre: Editora da UFRGS, 2009. Disponível em: http://www.ufrgs.br/cursopgdr/downloadsSerie/derad005.pdf. Acesso em: 23 dez. 2018.

TARDIF, M; LESSARD, C. O ofício de professor. História, perspectivas e desafios internacionais. Tradução Lucy Magalhães. 2. Ed. Petrópolis: Vozes, 2008.

THIOLLENT, Michel. Metodologia da pesquisa-ação. São Paulo: Cortez, 2009.

ZWARG, Joanna Durand; ARF, Lucilene Machado Garcia; BARREDA, Suzana Vinicia Mancilla. Formación de profesores de español en Corumbá (MS): perspectivas fronterizas y desafíos. In: MIRANDA, Cícero. La lengua española en Brasil: Enseñanza, formación de professores y resistencia. Brasília: Consejeria de Educación da Embaixada, 2018, p 19-27. 